\title{
BÍNA DIŞ DUVARLARINDA FARKLI YALITIM MALZEMESİ VE HAVA BOŞLUĞU KULLANIMININ, BİRİM ALANDAKİ ENERJİ TASARRUFU VE KİŞI BAŞI EMİSYON HESAPLAMALARINDA YENİ BİR YAKLAŞIM
}

\author{
Mustafa ERTÜRK \\ Balıkesir Üniversitesi, Balıkesir Meslek Yüksekokulu, Elektrik ve Enerji Bölümü, Balıkesir \\ merturk@balikesir.edu.tr
}

(Geliş/Received: 08.06.2015; Kabul/Accepted: 12.08.2015)

\begin{abstract}
ÖZET
Ankara'da bulunan binalar için: yalıtım malzemesiyle birlikte hava boşluğu kullanılarak optimum yalıtım kalınlığı (OYK), toplam maliyet, enerji tasarrufu, geri ödeme süresi (GÖS) hesaplanmıştır. Baca gazı salınım hesaplamaları için ilde bulunan binaların, toplam dış duvar yüzey alanı ve nüfus sayısı dikkate alınarak yıllık kişi başı yakıt tüketimi emisyonu (YTEM) yaklaşımı getirilmiştir. Yapılan analizlerde; yakıt olarak doğal gaz ve kömür kullanılması, bina dıș duvarlarında (sandviç duvar) yalıtım malzemesi olarak ekstrude polistren köpük (XPS), taşyünü ve ekspande polistren (EPS) ile birlikte dört farklı kalınlıkta hava boşluğu kullanılmıştır. Yakıt olarak doğalgaz kullanıldığında ve yalıtım malzemesi olan XPS'e $4 \mathrm{~mm}$ hava boşluğu ilave edildiğinde OYK 9,2 cm' den 3,4 cm' e düşmekte, GÖS 1.509 yıldan 1.320 yıla düşmekte, toplam maliyet de \%28 azalmakta, yıllık kazanç ise \%96 artmaktadır. Ayrıca kömür için optimum yalıtım kalınlığı 10,8 cm'den 5,0 cm'ye düştüğü, toplam maliyetin \%24 azaldığı, geri ödeme süresinin de 1.426 yıldan 1.292 yıla düştüğü, yıllık kazancın ise $\mathrm{m}^{2}$ başına \%94 arttığı hesaplanmıştır. 2014 yılı nüfus ve meskene ait elektrik abone sayıları baz alınarak yapılan hesaplamalara göre; doğalgaz kullanıldığında, yalıtımsız binaya göre, $4 \mathrm{~cm}$ XPS ve $4 \mathrm{~cm}$ hava boşluğu eklenmesi halinde $\mathrm{CO}_{2}$ salınımının \%82 azalacağı, belirlenmiştir. Kömür kullanılması durumunda ise $\mathrm{CO}_{2}$ ve $\mathrm{SO}_{2}$ oranlarının \% 82 azalacağı tespit edilmiştir.
\end{abstract}

Anahtar Kelimeler: Hava boşluğu kalınlığı, optimum yalıtım kalınlığı, ömür maliyet analizi, enerji tasarrufu, hava kirliliği, Ankara

\section{A NEW APPROACH TO CALCULATE THE ENERGY SAVING PER UNIT AREA AND EMISSION PER PERSON IN EXTERIOR WALL OF BUILDING USING DIFFRENT INSULATION MATERIALS AND AIR GAP}

\begin{abstract}
Optimal insulation thickness (OIT), total cost, energy savingsandpayback period (PP) has been calculated by using air gap together with insulation materials in buildings located in Ankara. The analysis of the exhaust emission rate has been carried out by calculating the total outer wall surface area of buildings and populations in the province. In these analysis, natural gas and coal as fuel, extruded polystyrene foam (XPS), mineral wool and expanded polystyrene (EPS) as insulation material were used with four different thicknesses of air gap combinations at exterior walls of building (sandwich walls). Whennatural gas is used as fuel and $4 \mathrm{~cm}$ air gap is introduced to XPS as insulating material, optimal insulation thickness (OIT) reduces to $3.4 \mathrm{~cm}$ from $9.2 \mathrm{~cm}$, payback period (PP) decrease from 1.509 to 1.320 years. This results in by $28 \%$ reduction in the total cost, while annual savings were significantly increased to $96 \%$ in $\mathrm{m}^{2}$. When coal is used as fuel with the same insulation material parameters applied above, (OIT) reduces to $5.00 \mathrm{~cm}$ from $10.8 \mathrm{~cm}$, payback period (PP) decrease from 1.426 to 1.292 years, which results in by $24 \%$ reduction in the total cost with an increase to $94 \%$ in $\mathrm{m}^{2}$ for annual savings. According to our calculations based on total population and residential subscribers to electricity in $2014, \mathrm{CO}_{2}$ emissionrate for natural gas usage are found to be reduced by $82 \%$ when $4 \mathrm{~cm}$ insulating material with $4 \mathrm{~cm}$ air gap is used compared to building without insulation. When coal is used for heating, $\mathrm{CO}_{2}$ and $\mathrm{SO}_{2}$ emissions rates are calculated to be reduced by $82 \%$.
\end{abstract}


Keywords: Air gap thickness, optimal insulation material thickness, life-cycle cost analysis, energy saving, air pollution, Ankara

\section{GÍRİŞ (INTRODUCTION)}

Teknolojik gelişmelerin yaşamın bütün alanlarında baş döndürücü hıla ilerlemesi enerjiye duyulan talebi de aynı hızla artırmıştır. Bu durum uluslararası ve ulusal düzeyde bir takım tedbirlerin alınmasını zorunlu hale getirmiştir. Enerjinin verimli olarak kullanılması için geliştirilen politikalar, üretici ve tüketicileri minimum enerji maksimum verim konusunda teşvik etmektedir. Isı yalıtımı; iletim (kondüksiyon), taşınım (konveksiyon) ve ışınım (radyasyon) yoluyla gerçekleşen 1sı akış hızını azaltan malzeme ya da malzemeler kombinasyonudur. Is1 yalıtım malzemeleri, içerdikleri sayısız mikroskopik kapalı hava hücrelerinin (bünyelerindeki havanın hareket etmesine izin vermeyerek) taşınım ile olan 1sı transferini engellemesi sonucu, 1sı akısına direnç gösterirler. Isıl direnci gösteren, yalıtım malzemesi değil, yalıtım malzemesinin bünyesinde bulunan hava hücreleridir Küçük hücre boyutuna ve kapalı hücre yapısına sahip 1sı yalıtım malzemeleri aynı zamanda, radyasyon etkisini de azaltır [1]. Konutlarda tüketilen enerjinin \%80'inin 1sıtma ve soğutma amaçlı kullanıldığı Türkiye'de, 1sı yalıtım teknolojileri sayesinde enerjiden yüksek oranda tasarruf sağlanabilir. Uygun bir biçimde yalıtım yapılmış binaların yalıtım maliyeti, bina ömrü boyunca kendini birçok kez geri ödeyebilecek durumdadır. Yapılan yalıtım ile birlikte birlikte enerji tüketimi azalacağı gibi buna bağlı olarak da oluşan baca gazı emisyonları (BGE) da azalmaktadır. Binalarda 1S1 yalıtımının ekonomik ve çevresel boyutunu irdeleyen farklı çalışmalar literatürde bulunmaktadır. Bolattürk, güneş radyasonunu dikkate alarak, Keçebaş ve Kayfeci'de soğuk oda tasarımı için optimum yalıtım kalınlığı (OYK) üzerinde durmuşlardır [2, 3]. Gölcü vd. Denizli için, Öztuna Edirne için, Deniz vd. Muğla için $(\mathrm{OYK})$ ve enerji tasarrufları üzerinde durmuşlardır [46]. Yıldız v.d çalışmasında Ankara için (OYK) ve sera gazı salınımını hesaplamış olup, yakıt olarak kömür, yalıtım malzemesi olarak ta cam yünü kullanılması durumunda optimum yalıtım kalınlığ $0,06 \mathrm{~m}$ olduğunu, $\mathrm{CO} 2$ salınımında ise $\% 35$ azalma tespit etmişlerdir [7]. Yu, Çin'de Daouas ise Tunus'ta farklı yötemler kullanarak (OYK) üzerinde durmuşlardır [8, 9]. Al-Khawaja, Çay, Balo vd., Aksoy ve Aytaç, farklı çalışmalarda yalıtım malzemelerinin (OYK) üzerinde durmuşlar ve en iyi yalıtım malzemesi tespit etmeye çalışmışlardır [1013]. Mahlia vd. Maldivler için sera gazı salınımı ve (OYK) hesabı yapmıştır [14]. Gürel ve Daşdemir, Türkiye'nin dört farklı 1sı bölgesinden iller için diş duvar yalıtımının optimum kalınlıkta yapılması durumunda, salınan zararlı gazların \% 65-75 oranında azaldığını tespit etmiştir [15]. Kurt, Karabük ilinde, yalıtımlı duvar da hava boşluğunun sırasıyla 2, 4, 6 $\mathrm{cm}$ bırakılması durumunda, yalıtımlı hava boşluksuz duvara oranla, $\mathrm{CO}_{2}$ ve $\mathrm{SO}_{2}$ salınımında ortalama \%54,46’ya varan azalma olabileceğini göstermiştir [16]. Mihliyanlar vd., 2 ve 5 katlı iki farklı binada, TS 825 (2008) "Binalarda Isı Yalıtım Kurallarına göre binalarda yalıtım düzeyinin iyileştirilmesi ile BGE azalmanın değişimi ve buna bağlı olarak hava kirliliğindeki iyileşmeyi değerlendirmişlerdir [17]. Mahlia ve İqbal, Maldivler' de yakıt türüne göre $\mathrm{CO}_{2}$ ve $\mathrm{SO}_{2}$ miktarlarındaki azalmayı değerlendirmişlerdir. Duvar bileşenleri içerisinde hava boşluğu kullanılması durumunda (OYK)' nın düştüğü, $\mathrm{CO}_{2}$ emisyonunda \% 25 , toplam baca gazı emisyonunda ise $\% 77$ 'ye varan azalmalar olduğu görülmüştür [18]. Gürel vd., yakıt olarak kömür kullanıldığında OYK ve enerji tasarrufunun sirasiyla $13,4 \mathrm{~cm}$ ve $117,14 \mathrm{TL} / \mathrm{m}^{2}$ olduğunu göstermiştir. Yakıt olarak doğal gaz kullanımında ise bu değerler sırasıyla $11,6 \mathrm{~cm}$ ve 88,39 TL $/ \mathrm{m}^{2}$ olarak bulunmuştur. Ayrıca OYK'nın, $\mathrm{CO}_{2}$ ve $\mathrm{SO}_{2}$ emisyonlarının yakıt tipine bağlı olarak $\% 85$ 'e kadar azaldığı hesaplanmıştır [19].

\section{MATERYAL VE METOT (MATERIALS AND METHODS)}

Bu çalışmada, Ankara'da yakıt olarak doğal gaz ve kömür, yalıtım malzemesi olarak XPS, EPS ve taş yünü kullanılması durumunda duvar bileşenlerinde bırakılacak olan hava boşluğunun, (OYK), toplam maliyet, enerji tasarrufu, geri ödeme süresi ve çevre kirliliğine etkisi incelenmiştir. Ayrıca bu çalışma içerisinde, Ankara'nın nüfusuna oranla yıllık kişi başına düşen BGE'ları hesaplanmıştır.

\subsection{Bina Dış Duvar Konstrüksiyonu (The Wall Construction of Bulding)}

Betonarme konutlarda kiriş genişliği minimum 25 cm'den başlamak üzere $30 \mathrm{~cm}$ ' ye kadar baz alınıp, yüke göre kiriş yükseklikleri hesaplanmaktadır [20].

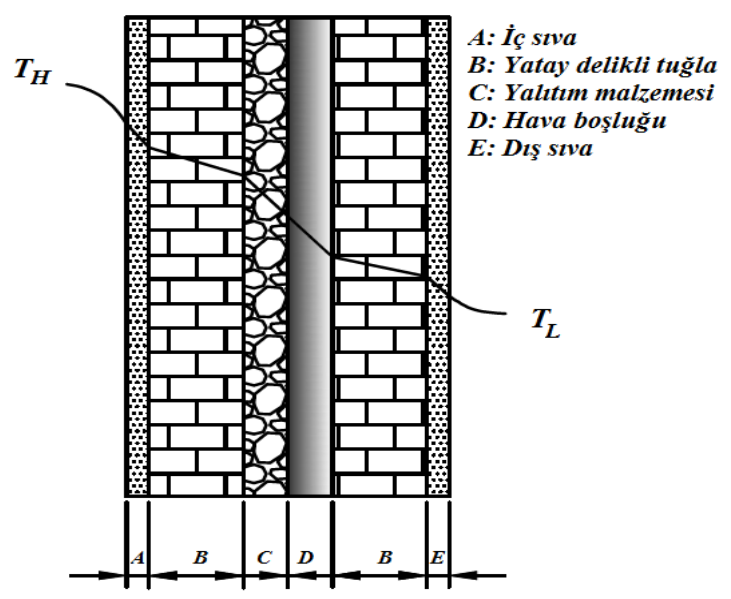

Şekil 1. Çalışmada kullanılan duvar konstrüksiyonu (The wall construction used in the study) 
Tablo 1. Kullanılan yakıta ait özellikler (The properties of the fuel used)

\begin{tabular}{lllll}
\hline Yakıt & Fiyat & LHV & $\boldsymbol{\eta}$ & Kimyasal Formül \\
\hline Doğal Gaz & $0,64 \$ / \mathrm{m}^{3}$ & $34,526 \times 10^{6} \mathrm{~J} / \mathrm{m}^{3}$ & 0,93 & $\mathrm{C}_{1.05} \mathrm{H}_{4} \mathrm{O}_{0.034} \mathrm{~N}_{0.022}$ \\
Kömür & $0,5 \$ / \mathrm{kg}$ & $29,295 \times 10^{6} \mathrm{j} / \mathrm{kg}$ & 0,65 & $\mathrm{C}_{5.85} \mathrm{H}_{5.26} \mathrm{O}_{1.13} \mathrm{~S}_{0.008} \mathrm{~N}_{0.077}$ \\
\hline
\end{tabular}

$\mathrm{Bu}$ çalışma da betonarme yapıların tasarımı ve yapım kuralarına uygun olarak kiriş genişliği $30 \mathrm{~cm}$ olarak alınmıştır. Hesaplamalarda kullanılan dış duvar konstrüksiyonu Şekil 1'de gösterilmiştir. Duvar bileşenleri, $2 \mathrm{~cm}$ iç sıva (A), 8,5 cm yatay delikli tuğla (B), yalıtım malzemesi (C), hava boşluğu (D), 8,5 cm yatay delikli tuğla (B) ve $3 \mathrm{~cm}$ diş sıvadan (E) oluşmaktadır.

\subsection{Bina Isıtma Enerji İhtiyacının Hesaplanması (The Calculation of the Heating Energy Needs of Buildings)}

Kapalı hacimlerdeki ısı kayıpları; dış duvar, çatı, döşeme, pencere gibi yapı bileşenleri nedeniyle oluşmaktadır. Sandviç duvar tipi bu çalışma için seçilmiştir. Hesaplamalarda, 1sı kayıplarının sadece dış duvar yüzeyinde olduğu kabul edilmiştir. Dış duvar birim alanındaki 1sı kaybı, Eşitlik (1) ile hesaplanır.

$q=U\left(T_{b}-T_{o}\right)$

$U$ dış duvarın toplam ısı transfer direncini $\left[\mathrm{W} / \mathrm{m}^{2} \mathrm{~K}\right]$, $T_{b}$ denge sıcaklığını $\left[{ }^{\circ} \mathrm{C}\right]$ ve $T_{o}$ referans alınacak iç ortam sıcaklığını $\left[{ }^{\circ} \mathrm{C}\right]$ ifade etmektedir. Çalışmada kullanılan dış duvar için toplam ısı transfer direnci Eşitlik (2) ile hesaplanabilir.

$U=\frac{1}{R_{i}+R_{w}+R_{\text {ins }}+R_{a}+R_{d}}$

Burada $R_{i}$ ve $R_{d}$ sırasıyla iç ve diş yüzeydeki 1 sı taşınım katsayılarını, $R_{w}$ yalıtımsız duvarın toplam ısıl direncini, $R_{i n s}$ yalıtım malzemesi isıl direncini, $R_{a}$ ise hava boşluğu 1sıl direncini ifade etmekte olup Eşitlik (3) ve Eşitlik (4) ile hesaplanır.

$$
\begin{aligned}
& R_{\text {ins }}=\frac{x}{k_{\text {ins }}} \\
& R_{a}=\frac{x}{k_{a}}
\end{aligned}
$$

$x$ yalıtım malzemesi kalınlığını $(\mathrm{m}), k_{\text {ins }}$ yalıtım malzemesinin, $k_{\text {hava }}$ 'nın 1sı iletim katsayılarını $[\mathrm{W} / \mathrm{mK}]$ ifade etmektedir.

Yalıtımsız duvarın 1sıl direnci, hava boşluğu ile birlikte $R_{w t}$ ile ifade edilirse, toplam 1S1 transfer katsayısı Eşitlik (5) ile hesaplanır.

$$
U=\frac{1}{R_{w t}+R_{i n s}}
$$

Isıtma için harcanan yıllık enerji miktarı Eşitlik (6) ile hesaplanir.
$E_{A}=\frac{C_{f} U I D S}{L H V \eta}$

$C_{f}$; yakıt maliyetini, IDS; 1sıtma derece saat değerini, $L H V$; yakıtın alt 1 sil değerini $\left(\mathrm{J} / \mathrm{m}^{3}\right), \eta$; 1 sitma sisteminin verimini ifade etmektedir. Kullanılan yakıtlara ait özellikler Tablo 1'de verilmiştir.

\subsection{Optimum Yalıtım Kalınlığının Belirlenmesi (Determination of Optimum Insulation Thickness)}

Bina dış duvarlarındaki yalıtım, ısıtma ve soğutma sistemleri için gerekli enerjinin etkin bir şekilde kullanılmasını sağlar. Uygun yalıtım kalınlığı; dış ortam sıcaklığı, dış duvar yapı bileşenleri ve yalıtım malzemesinin özellikleri gibi parametrelerle yakından ilgilidir.

OYK hesaplamaların da, bir takım değişken parametreler vardır. $\mathrm{Bu}$ değişkenler; binanın bulunduğu il, bina dış duvarının bileşenleri, kullanılan yalıtım ve yapı malzemeleri, yakıt fiyatları, yakma sisteminin verimi ve yakıtın alt 1 sıl değeridir. Yalıtım kalınlığının artması; kış aylarında ısı kaybını, yaz aylarında ise 1sı kazancını azaltacaktır. Ancak yalıtım kalınlığının artmasının bir maliyeti vardır ve yalıtım kalınlığı arttıkça 1sı iletimindeki azalma belli bir değerden sonra azalmaktadır. Dolayısıyla yalıtım kalınlığ 1 için optimum bir değer söz konusudur. OYK hesaplamalarında, toplam 1sitma maliyetinin minimum olduğu noktada (OYK) ve yakıt maliyeti tespit edilmektedir. OYK hesaplamalarında ömür maliyet analiz yöntemi kullanılmaktadır [21-24]. Bu çalışmada, ömür maliyet analizine göre 7-12 numaralı eşitlikler [25, 26] kullanılarak OYK hesaplanmıştır. Toplam 1sitma maliyetinin hesabında ise binanın ömür süresi $(N)$ ile şimdiki değer faktörü $\left(P_{l}\right)$ birlikte değerlendirilmiştir. $P_{l}$; faiz oranı $(i)$ ve enflasyon oranına (d) bağlı olarak değişir ve Eşitlik (7)'ye göre hesaplanmıştır. Hesaplamalarda $i=\% 5$ ve $d=\% 5$ alınmıştır [27].

$P_{1}=\frac{N}{1+i} ; i=d$ ise

Yalıtımın ilk yatırım maliyeti $\left(\mathrm{P}_{2}\right)$, işletme giderleri ve bakım giderleri dikkate alınarak, Eşitlik (8) de verilmiştir.

$P_{2}=1+P_{1} M_{S^{-}} \frac{R_{v}}{(1+d)^{N}}$

Eşitlik(8) de, $M_{s}$; yıllık bakım ve işçilik giderlerinin ilk alınan maliyet değerine oranını, $R_{v}$; perakende satış değerinin ilk satış değerine oranını göstermektedir. Buna göre bakım ve işçilik 
maliyetleri sıfir kabul edilirse $P_{2}$ değeri 1 alınabilir. Yalıtım maliyeti $\left(C_{\text {ins }}\right)$ ise, yalıtım malzemesinin birim hacim fiyatı $\left(C_{i}\right)$ ile yalıtım malzemesi tabaka kalınlığının $(x)$ çarpımına eşit olup, Eşitlik (9)'a göre hesaplanmıştır.

$C_{\text {ins }}=C_{i} x$

Bina dış duvarı birim alanından elde edilecek enerji tasarrufu $(S)$, Eşitlik (10) ile verilmiştir.

$S=P_{1} E_{A^{-}} P_{2} C_{\text {ins }}$

Yalıtılmış bir binanın toplam ısıtma maliyeti $\left(C_{\text {too }}\right)$; sistemle ilgili tüm harcamaların toplamından oluşan ömür maliyet analizi kullanılarak Eşitlik (11)’ de verilmiştir.

$C_{\text {top }}=P_{1} E_{A}+P_{2} C_{\text {ins }}$

Optimum yalıtım kalınlığ $\left(_{\text {opt }}\right)$, y1llık maliyetin en düșük olduğu nokta olarak ifade edilebilir. $\mathrm{Bu}$ noktada yapılacak olan yalıtım, minimum maliyet ve maksimum enerji tasarrufu sağlayacaktır. $\mathrm{Bu}$ çalışmada OYK, Eşitlik (12) yardımıyla hesaplanmıştır.

$X_{o p t}=\left(\frac{I D S C_{f} P_{1} k_{i n s}}{P_{2} L H H V C_{i} \eta}\right)^{1 / 2}-k_{i n s} R_{w t}$

Yapılan yatırımın somut olarak geri dönme süresinde $\left(P_{t}\right)$ önemli bir parametredir. Bunun için de yapılan yatırıma karşılık, geri ödeme süresi Eşitlik (13) ile hesaplanmaktadır. Hesaplamalarda kullanılan parametreler, Tablo 2'de verilmiştir.

$P_{t}=\frac{L H V C_{i} P_{2} \eta\left(R_{w t} x+R_{w t}^{2} k_{i n s}\right)(1+i)}{C_{f} I D S}$

Tablo 2. Hesaplamalarda kullanılan parametreler (The parameters used in the calculations)

\begin{tabular}{|c|c|}
\hline Parametre & Değer \\
\hline Derece-saat & 64200 Derece-saat \\
\hline \multicolumn{2}{|l|}{ Yalıtım } \\
\hline \multicolumn{2}{|l|}{ XPS } \\
\hline Isı iletim katsayısı, $k$ & $0,036 \mathrm{~W} / \mathrm{mK}$ \\
\hline Maliyet, $C_{i}$ & $120 \$ / \mathrm{m}^{3}$ \\
\hline \multicolumn{2}{|l|}{ EPS } \\
\hline Isı iletim katsayısı, $k$ & $0,04 \mathrm{~W} / \mathrm{mK}$ \\
\hline Maliyet, $C_{i}$ & $85 \$ / \mathrm{m}^{3}$ \\
\hline \multicolumn{2}{|l|}{ Taş yünü } \\
\hline Isı iletim katsayısı, $k$ & 0,04 \\
\hline Maliyet, $C_{i}$ & $100 \$ / \mathrm{m}^{3}$ \\
\hline \multicolumn{2}{|l|}{ Hava } \\
\hline Isı iletim katsayısı, $k$ & $0,025 \mathrm{~W} / \mathrm{mK}$ \\
\hline Maliyet, $C_{i}$ & 0 \\
\hline \multicolumn{2}{|l|}{ Dıș duvar } \\
\hline İç sıva & $0,02 \mathrm{~m}$ \\
\hline Isı iletim katsayısı, $k$ & $0,872 \mathrm{~W} / \mathrm{mK}$ \\
\hline Tuğla & $0,085 \mathrm{~m}$ \\
\hline Isı iletim katsayısı, $k$ & $0,45 \mathrm{~W} / \mathrm{mK}$ \\
\hline Diş sıva & $0,03 \mathrm{~m}$ \\
\hline Isı iletim katsayısı, $k$ & $1,4 \mathrm{~W} / \mathrm{mK}$ \\
\hline $\boldsymbol{U}$ & $0,58 \mathrm{~m}^{2} \mathrm{~K} / \mathrm{W}$ \\
\hline Ömür, $N$ & $10 \mathrm{y} 11$ \\
\hline$P_{1}$ & 9.52 \\
\hline$P_{2}$ & 1 \\
\hline
\end{tabular}

\subsection{Baca Gazı Emisyon Hesabı (The Calculation of} Exhaust Emission )

Bina dış duvarlarında uygulanan yalıtım, yakıt tüketimini ve BGE'da azaltacaktır. Kullanılan yakıtların genel yanma formülü aşağıdaki Eşitlik (14)'de verilmiştir [24]. Eşitlik (14)'de $\mathrm{NO}_{\mathrm{x}}$ ve $\mathrm{CO}$ emisyonları ihmal edildiğinden eşitliğe alınmamıştır.

$$
\begin{aligned}
& \mathrm{C}_{x} \mathrm{H}_{z} \mathrm{O}_{w} \mathrm{~S}_{y} \mathrm{~N}_{t}+a \mathrm{~A}\left(\mathrm{O}_{2}+3,76 \mathrm{~N}_{2}\right) \rightarrow x \mathrm{CO}_{2}+\frac{z}{2} \mathrm{H}_{2} \mathrm{O} \\
& +y \mathrm{SO}_{2}+(a-1) \mathrm{AO}_{2}+\mathrm{BN}_{2}
\end{aligned}
$$

Yakıt içerisindeki, kimyasalların yanabilmesi için gerekli olan oksijen ve azot miktarı aşağıda verilen Eşitlik (15) ve Eşitlik (16) ile elde edilmiştir.

$A=\left(x+\frac{z}{4}+y-\frac{w}{2}\right)$

$B=3,76 a\left(x+\frac{z}{4}+y+\frac{w}{2}\right)+\frac{t}{2}$

Yıllık yakıt tüketimi $\left(m_{f A}\right)\left[\mathrm{kg} / \mathrm{m}^{2}\right.$-yıl $]$ Eşitlik (17) ile hesaplanmaktadır.

$m_{f A}=\frac{3600 I D S K}{L H V \eta}$

$M$, yakıtın mol ağırlığı eşitlik (18) ile hesaplanarak elde edilir. $1 \mathrm{~kg}$ yakıtın yanması sonucu ortaya çıkacak emisyon oranları Eşitlik (19) ve Eşitlik (20) ile hesaplanmıştır.

$M=12 x+32 y+z+14 t+16 w$

$M_{\mathrm{CO}_{2}}=\frac{x \mathrm{CO}_{2}}{\mathrm{M}}\left(\mathrm{kgCO}{ }_{2} / \mathrm{kg}\right)$

$M_{\mathrm{SO}_{2}}=\frac{y \mathrm{SO}_{2}}{\mathrm{M}}\left(\mathrm{kgSO}_{2} / \mathrm{kg}\right)$

Toplam yakıt miktarının belirlendiği $m_{f A}$ eşitliği üzerinden, yanma sonucu açığa çıkacak toplam gaz emisyonları aşağıda verilen Eşitlik (21) ve (22) ile bulunur.

$M_{\mathrm{CO}_{2}}=\frac{44 x}{M} m_{f}$

$M_{\mathrm{SO}_{2}}=\frac{64 y}{M} m_{f}$

\section{ANALIZ SONUÇLARI VE TARTIŞMA (RESULTS OF ANALYSIS AND DISCUSSION)}

Bu çalışmada, 2014 yılı nüfus sayımına göre Ankara ili nüfusu 4.956.542 kişi olarak alınmıştır [28]. Yakıt türü olarak doğal gaz ve kömür, yalıtım malzemesi olarak da XPS, EPS, taş yünü ve havanın kullanıldığı varsayılmıştır. Duvar bileşenlerinde, optimum hava boşluğu kalınlığı, birim alandaki toplam maliyet, tasarruf edilen enerji miktarları hesaplanmıştır. Ayrıca 
çalışmada kullanılan bu iki yakıt türüne ve dört farklı yalıtım malzemesine göre atmosfere salınan (BGE) hesaplanmıştır.

\subsection{Yakıt Türünün Optimum Yalıtım Kalınlığı ve Hava Boşluğuna Etkisi (The Effect of Type of Fuel on Optimum Insulation Thickness and Air Gap )}

Yakıt türü olarak doğal gaz kullanıldığında, üç farklı yalıtım malzemesi için dış duvar bileşenlerinde bırakılacak optimum hava boşluğu, geri ödeme süreleri, y1llık kazançlar ve toplam maliyetler Tablo 3 $(a, b, c)$ 'de verilmiştir.

Tablo 3. Doğal gaz için üç farklı yalıtım malzemesine göre hava boşluğunun etkileri (The effects of air gap for three different insulation materials for natural gas)

\begin{tabular}{|c|c|c|c|c|c|}
\hline XPS & \multicolumn{5}{|c|}{ Hava Boşluğu $(\mathrm{cm})$} \\
\hline & $\mathbf{0}$ & 1 & 2 & 3 & 4 \\
\hline $\mathrm{X}_{\mathrm{op}}(\mathrm{cm})$ & 9,2 & 7,7 & 6,3 & 4,8 & 3,4 \\
\hline $\begin{array}{l}\text { Top.Mal } \\
\text { (TL/m²-y1l) }\end{array}$ & 24,48 & 22,75 & 21,03 & 19,30 & 17,57 \\
\hline GÖS (y1l) & 1,509 & 1,457 & 1,408 & 1,363 & 1,320 \\
\hline $\begin{array}{l}\text { Kazanç } \\
\left(\mathrm{TL} / \mathrm{m}^{2} \text {-yll) }\right.\end{array}$ & 1,515 & 3,600 & 7,658 & 16,636 & 41,329 \\
\hline \multicolumn{6}{|c|}{ (a) } \\
\hline EPS & \multicolumn{5}{|c|}{ Hava Boşluğu $(\mathrm{cm})$} \\
\hline & $\mathbf{0}$ & 1 & 2 & 3 & 4 \\
\hline $\mathrm{X}_{\mathrm{op}}(\mathrm{cm})$ & 11,8 & 10,2 & 8,6 & 7,0 & 5,4 \\
\hline $\begin{array}{l}\text { Top.Mal } \\
\text { (TL/m²-y1l) }\end{array}$ & 21,97 & 20,61 & 19,25 & 17,89 & 16,53 \\
\hline GÖS (y1) & 1,509 & 1,457 & 1,408 & 1,363 & 1,320 \\
\hline $\begin{array}{l}\text { Kazanç } \\
\left(\mathrm{TL} / \mathrm{m}^{2}-\mathrm{y} 1 \mathrm{l}\right)\end{array}$ & 1,435 & 3,254 & 6,452 & 12,583 & 25,98 \\
\hline \multicolumn{6}{|c|}{ (b) } \\
\hline TAŞ YÜNÜ & \multicolumn{5}{|c|}{ Hava Boşluğu $(\mathrm{cm})$} \\
\hline & $\mathbf{0}$ & 1 & 2 & 3 & 4 \\
\hline $\mathrm{X}_{\mathrm{op}}(\mathrm{cm})$ & 10,7 & 9,1 & 7,5 & 5,9 & 4,3 \\
\hline $\begin{array}{l}\text { Top.Mal } \\
\left(\mathrm{TL} / \mathrm{m}^{2}-\mathrm{y} 1 \mathrm{l}\right)\end{array}$ & 23,65 & 22,05 & 20,45 & 18,85 & 17,25 \\
\hline GÖS (yıl) & 1,484 & 1,437 & 1,393 & 1,351 & 1,312 \\
\hline $\begin{array}{l}\text { Kazanç } \\
\left(\mathrm{TL} / \mathrm{m}^{2} \text {-y1l) }\right.\end{array}$ & 1,490 & 3,467 & 7,197 & 15,038 & 34,842 \\
\hline
\end{tabular}

$$
\text { (c) }
$$

Bu tabloda görüldüğü üzere, yalıtım malzemesi olarak sadece XPS kullanıldığında, OYK 9,2 cm iken, bu duvar bileşenine $4 \mathrm{~cm}$ hava boşluğu eklendiğinde $O Y K$ 3,4 cm'e, toplam maliyeti ise y1llık $\mathrm{m}^{2}$ başına 24.48 TL'den 17.57 TL'ye geri ödeme süresi 1.509 yıldan 1.320 yıla düşürmekte, yıllık kazancıda \%96 oranında artırmaktadır.

Yakıt türü olarak kömür, üç farklı yalıtım malzemesi ve farklı hava boşluğu kullanıldığında hesaplama sonuçları Tablo 4 (a, b, c)'de verilmiştir.
Tablo 4. Kömür için üç farklı yalıtım malzemesine göre hava boşluğunun etkileri (The effects of air gap for three different insulation materials for coal)

\begin{tabular}{|c|c|c|c|c|c|}
\hline XPS & \multicolumn{5}{|c|}{ Hava Boşluğu $(\mathrm{cm})$} \\
\hline & $\mathbf{0}$ & 1 & 2 & 3 & 4 \\
\hline $\mathrm{X}_{\mathrm{op}}(\mathrm{cm})$ & 10,8 & 9,4 & 7,9 & 6,5 & 5,0 \\
\hline $\begin{array}{l}\text { Top.Mal } \\
\text { (TL/m²-y1l) }\end{array}$ & 28,43 & 26,70 & 24,97 & 23,24 & 21,52 \\
\hline GÖS (yıl) & 1,426 & 1,390 & 1,356 & 1,323 & 1,292 \\
\hline $\begin{array}{l}\text { Kazanç } \\
\text { (TL/m²-y1l) }\end{array}$ & 1,425 & 3,203 & 6,297 & 12,131 & 24,561 \\
\hline \multicolumn{6}{|c|}{ (a) } \\
\hline TAŞ YÜNÜ & \multicolumn{5}{|c|}{ Hava Boşluğu $(\mathrm{cm})$} \\
\hline & $\mathbf{0}$ & 1 & 2 & 3 & 4 \\
\hline Xop (m) & 12,6 & 11,0 & 9,4 & 7,8 & 6,2 \\
\hline $\begin{array}{l}\text { Top.Mal } \\
\text { (TL/m2-y1l) }\end{array}$ & 27,45 & 25,85 & 24,25 & 22,65 & 21,05 \\
\hline GÖS (yıl) & 1,405 & 1,373 & 1,342 & 1,312 & 1,284 \\
\hline $\begin{array}{l}\text { Kazanç } \\
\text { (TL/m2-y1l) }\end{array}$ & 3,313 & 7,342 & 14,168 & 26,580 & 51,654 \\
\hline \multicolumn{6}{|c|}{ (b) } \\
\hline EPS & \multicolumn{5}{|c|}{ Hava Boşluğu $(\mathrm{cm})$} \\
\hline Xop (m) & $\begin{array}{c}\mathbf{0} \\
13,8\end{array}$ & $\begin{array}{c}\mathbf{1} \\
12,2\end{array}$ & $\begin{array}{c}\mathbf{2} \\
10,6\end{array}$ & $\begin{array}{c}\mathbf{3} \\
9,0\end{array}$ & $\begin{array}{c}\mathbf{4} \\
7,4\end{array}$ \\
\hline $\begin{array}{l}\text { Top.Mal } \\
\text { (TL/m²-y1l) }\end{array}$ & 25,47 & 24,11 & 22,75 & 21,39 & 20,03 \\
\hline GÖS (yıl) & 1,365 & 1,339 & 1,314 & 1,290 & 1,267 \\
\hline $\begin{array}{l}\text { Kazanç } \\
\text { (TL/m²-y1l) }\end{array}$ & 1,365 & 2,947 & 5,490 & 9,814 & 17,759 \\
\hline
\end{tabular}

$\mathrm{Bu}$ tabloda görüldüğü üzere yalıtım malzemesi olarak sadece XPS kullanıldığında, OYK 10,8 cm iken, bu duvar bileşenine $4 \mathrm{~cm}$ hava boşluğu eklendiğinde $O Y K$ 5,0 cm'e, toplam maliyeti ise yıllık $\mathrm{m}^{2}$ başına 28.43 TL'den 21.52 TL'ye düşürmekte, yıllık kazancıda \% 96 oranında artırmaktadır.

\subsection{Yalıtım Kalını̆̆ğı ve Hava Boşluğunun Baca Gazı Emisyonlarına Etkisi (The Effect of Insulation Thickness and Air Gap on Exhaust Emission)}

Enerji kaynaklarını, çevre üzerindeki etkilerinden bağımsız olarak ele almak mümkün değildir. Özellikle kömür ve linyit gibi fosil yakıtların yanması sonucu oluşan $\mathrm{CO}_{2}, \mathrm{SO}_{2}, \mathrm{NO}_{\mathrm{X}}$ emisyonları, atmosferik kirliliğin artmasında birinci derecede etkendir. Endüstriyel faaliyetler sonucunda, her yıl atmosfere yaklaşık 20 milyar ton $\mathrm{CO}_{2}, 100$ milyon ton kükürt bileșikleri, 2 milyon ton kurșun ve diğer zehirli kimyasal bileşikler salınmaktadır. $\mathrm{CO}_{2}$ ve $\mathrm{SO}_{2}$ emisyonları doğrudan doğruya tüketilen enerjinin miktarı ile orantılıyken, $\mathrm{NO}_{2}, \mathrm{CO}$ ve diğer uçucuların oluşturduğu emisyon seviyeleri ise kullanılan teknolojiye bağlıdır [29]. $\mathrm{Bu}$ yüzden bina dış duvarlarında uygulanacak yalıtım sayesinde açığa çıkan baca gazı salınımları da azalacaktır. $\mathrm{Bu}$ çalışmada makale metninin uzamaması için, baca gazı emisyon hesaplamalarında yalıtım malzemesi olarak XPS dikkate alınmıştır. 


\subsubsection{Yakıt Olarak Kömür Kullanılması Durumunda Kükürtdioksit Salınımı (The Amount of $\mathrm{SO}_{2}$ Emission in Case of Using Coal as Fuel)}

Bu çalışmada yakıt olarak kömür kullanılması halinde yalıtımsız ve farklı hava boşluğu kalınlıklarının kullanıldığg yalıtım malzemeleri için hesaplanan $\mathrm{SO}_{2}$ salınımları Tablo 5'te verilmiştir. Bu tabloda Ankara ili için yalıtımsız bir binanın sadece dış duvarlarından yılda $\mathrm{m}^{2}$ başına $0,461 \mathrm{~kg} \quad \mathrm{SO}_{2} \quad$ gazı salındı bulunmuştur. $\mathrm{Bu}$ binanın, pencereler ve balkon kapıları hariç dış duvar toplam yüzey alanı $100 \mathrm{~m}^{2}$ olduğu kabulüne göre yıllık 46,1 kg $\mathrm{SO}_{2}$ atmosfere salınmakta, aynı binada $4 \mathrm{~cm}$ yalıtım kalınlığ 1 ve $4 \mathrm{~cm}$ hava boşluğu uygulandığında salınan $\mathrm{SO}_{2}$ miktarı $8,1 \mathrm{~kg} /$ yıldır.

$\mathrm{Bu}$ karşılaştırmaya göre atmosfere salınan $\mathrm{SO}_{2}$ oranı \%82,4 azalmaktadır. Şekil 2'de dört farklı XPS yalıtım malzemesi kalınlığına göre $\mathrm{SO}_{2}$ salınım dağılımı verilmiştir. $\mathrm{Bu}$ şekilde en az salınım $4 \mathrm{~cm}$, daha sonra sirasiyla 3-2-1 cm yalitıml bileşenlerinde, en fazla salınım ise yalıtımsız yapı bileşeninde olduğu görülmektedir. Hareketli ortalama dağılım denklem takımı kullanıldığında $\mathrm{R}^{2}$ 'nin \%95,95'e kadar yakınsadığı Eşitlik (23) ile bulunmuştur.

$y=0.1627 e^{-8.616 x}$

$\mathrm{y}$, kişibaşı $\mathrm{SO}_{2}$ emisyon miktarını, $x$ ise optimum yalıtım kalınlığını göstermektedir.

4.2.2 Yakit Olarak Kömür Ve Doğal Gaz Kullanılması Durumunda Karbondioksit Salınımı (The Amount of $\mathrm{CO}_{2}$ Emission in Case of Using Natural Gas as Fuel.)

Ankara ili için yakıt olarak doğal gaz ve kömür kullanıldığında yalıtım kalınlığı ve hava boșluğuna göre $\mathrm{CO}_{2}$ salınımları Tablo 6' ve Tablo 7'de gösterilmiştir. Yalıtımsız bir binaya göre $4 \mathrm{~cm}$ yalıtım kalınlığı ve $4 \mathrm{~cm}$ hava boşluğu uygulamasında, diş duvardan yılda $\mathrm{m}^{2}$ başına atmosfere salınan $\mathrm{CO}_{2}$ oranı $\% 82,32$ azalmaktadır. Kömür ve doğal gaz için yalıtım malzemesi-hava boşluğu kalınlığına göre $\mathrm{CO}_{2}$ salınımları Şekil 3 ve Şekil 4'te verilmiştir.

Tablo 5. Yakıt olarak kömür kullanılması durumunda $\mathrm{SO}_{2}$ salınım miktarı $\left(\mathrm{kg} / \mathrm{m}^{2} \mathrm{y} 1 \mathrm{l}\right)$ (The amount of $\mathrm{SO}_{2}$ emission $\left(\mathrm{kg} / \mathrm{m}^{2}\right.$ year) in case of using coal as fuel.)

\begin{tabular}{|c|cccccccccc|}
\hline \multirow{2}{*}{ Hava Boşluğu (cm) } & \multicolumn{7}{|c|}{ SO $_{2}$ Emisyon Miktarı (kg/m $\mathbf{2}$ yıl) } \\
\cline { 2 - 11 } & \multicolumn{7}{|c}{ Yalıtım Kalını̆ı̆ı (cm) } \\
\cline { 2 - 10 } & 0 & 2 & 4 & 6 & 8 & 10 & 12 & 14 & 16 \\
\hline 0 & 0,461 & 0,236 & 0,158 & 0,119 & 0,096 & 0,080 & 0,068 & 0,060 & 0,053 \\
1 & 0,273 & 0,174 & 0,128 & 0,101 & 0,084 & 0,071 & 0,062 & 0,055 & 0,049 \\
2 & 0,194 & 0,138 & 0,108 & 0,088 & 0,074 & 0,064 & 0,057 & 0,051 & 0,046 \\
3 & 0,150 & 0,115 & 0,093 & 0,078 & 0,067 & 0,059 & 0,052 & 0,047 & 0,043 \\
4 & 0,123 & 0,098 & 0,081 & 0,070 & 0,061 & 0,054 & 0,049 & 0,044 & 0,040 \\
\hline
\end{tabular}

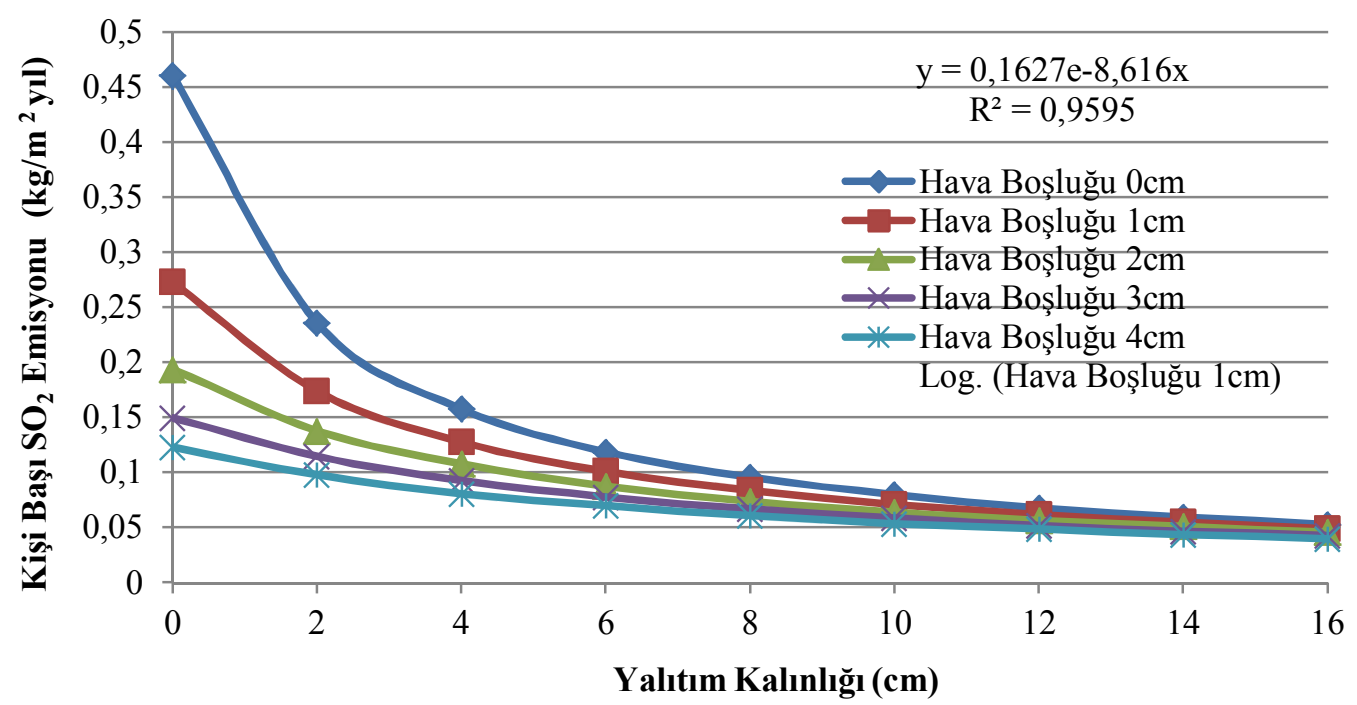

Şekil 2. Kömür için, yalıtım malzemesi-hava boşluğu kalınlığına göre kişi başı yıllık $\mathrm{SO}_{2}$ emisyon miktarı $\left(\mathrm{kg} / \mathrm{m}^{2} \mathrm{yll}\right)$ (The amount of $\mathrm{SO}_{2}$ emission $\left(\mathrm{kg} / \mathrm{m}^{2}\right.$ year) according to insulation material and air gap thicknesses for coal used as fuel 
Tablo 6. Doğal gaz kullanılması durumunda $\mathrm{CO}_{2}$ salınım miktarı $\left(\mathrm{kg} / \mathrm{m}^{2} \mathrm{y} 1\right)$ (The amount of $\mathrm{CO}_{2}$ emission $\left(\mathrm{kg} / \mathrm{m}^{2}\right.$ year) in case of using natural gas as fuel)

\begin{tabular}{|c|c|c|c|c|c|c|c|c|c|}
\hline \multirow{3}{*}{$\begin{array}{c}\text { Hava } \\
\text { Boşluğu } \\
\text { (cm) }\end{array}$} & \multicolumn{9}{|c|}{$\mathrm{CO}_{2}$ Emisyon Miktarı (kg/m² $\left.{ }^{2} \mathrm{ll}\right)$} \\
\hline & \multicolumn{9}{|c|}{ Yalıtım Kalınlığı $(\mathbf{c m})$} \\
\hline & 0 & 2 & 4 & 6 & 8 & 10 & 12 & 14 & 16 \\
\hline 0 & 117,679 & 60,214 & 40,458 & 30,463 & 24,428 & 20,389 & 17,496 & 15,322 & 13,629 \\
\hline 1 & 69,751 & 44,551 & 32,727 & 25,863 & 21,379 & 18,220 & 15,874 & 14,064 & 12,624 \\
\hline 2 & 49,565 & 35,354 & 27,476 & 22,470 & 19,006 & 16,468 & 14,528 & 12,997 & 11,757 \\
\hline 3 & 38,440 & 29,305 & 23,678 & 19,864 & 17,108 & 15,023 & 13,392 & 12,080 & 11,002 \\
\hline 4 & 31,394 & 25,023 & 20,802 & 17,799 & 15,554 & 13,812 & 12,421 & 11,284 & 10,338 \\
\hline
\end{tabular}

Tablo 7. Kömür kullanılması durumunda $\mathrm{CO}_{2}$ salınım miktarı $\left(\mathrm{kg} / \mathrm{m}^{2} \mathrm{y} 1 \mathrm{l}\right)$ (The amount of $\mathrm{CO}_{2}$ emission $\left(\mathrm{kg} / \mathrm{m}^{2}\right.$ year) in case of using coal as fuel)

\begin{tabular}{|c|c|c|c|c|c|c|c|c|c|}
\hline \multirow{3}{*}{$\begin{array}{c}\text { Hava } \\
\text { Boşluğu } \\
\text { (cm) }\end{array}$} & \multicolumn{9}{|c|}{$\mathrm{CO}_{2}$ Emisyon Miktarı $\left(\mathrm{kg} / \mathrm{m}^{2} \mathrm{yl}\right)$} \\
\hline & \multicolumn{9}{|c|}{ Yalıtım Kalınlığı $(\mathbf{c m})$} \\
\hline & 0 & 2 & 4 & 6 & 8 & 10 & 12 & 14 & 16 \\
\hline 0 & 223,828 & 114,516 & 76,940 & 57,931 & 46,454 & 38,773 & 33,271 & 29,137 & 25,917 \\
\hline 1 & 132,636 & 84,716 & 62,232 & 49,180 & 40,653 & 34,646 & 30,186 & 26,743 & 24,005 \\
\hline 2 & 94,251 & 67,228 & 52,248 & 42,727 & 36,142 & 31,315 & 27,626 & 24,714 & 22,357 \\
\hline 3 & 73,096 & 55,725 & 45,025 & 37,772 & 32,531 & 28,568 & 25,465 & 22,971 & 20,921 \\
\hline 4 & 59,697 & 47,583 & 39,556 & 33,846 & 29,577 & 26,264 & 23,619 & 21,457 & 19,658 \\
\hline
\end{tabular}

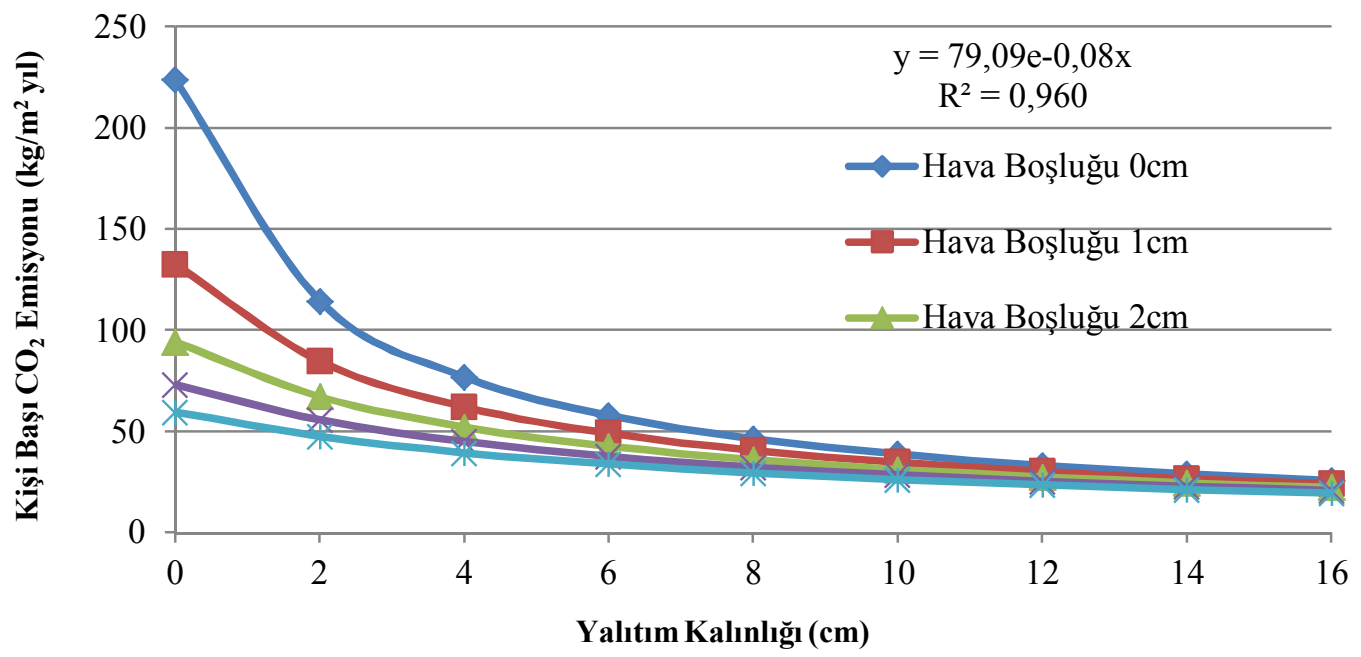

Şekil 3. Kömür için yalıtım malzemesi-hava boşluğu kalınlığına göre kişi başına düşen yıllık $\mathrm{CO}_{2}$ emisyon miktarl $\left(\mathrm{kg} / \mathrm{m}^{2} \mathrm{yl}\right.$ ) (The amount of $\mathrm{CO}_{2}$ emission $\left(\mathrm{kg} / \mathrm{m}^{2}\right.$ year) according to insulation material and air gap thicknesses for coal used as fuel)

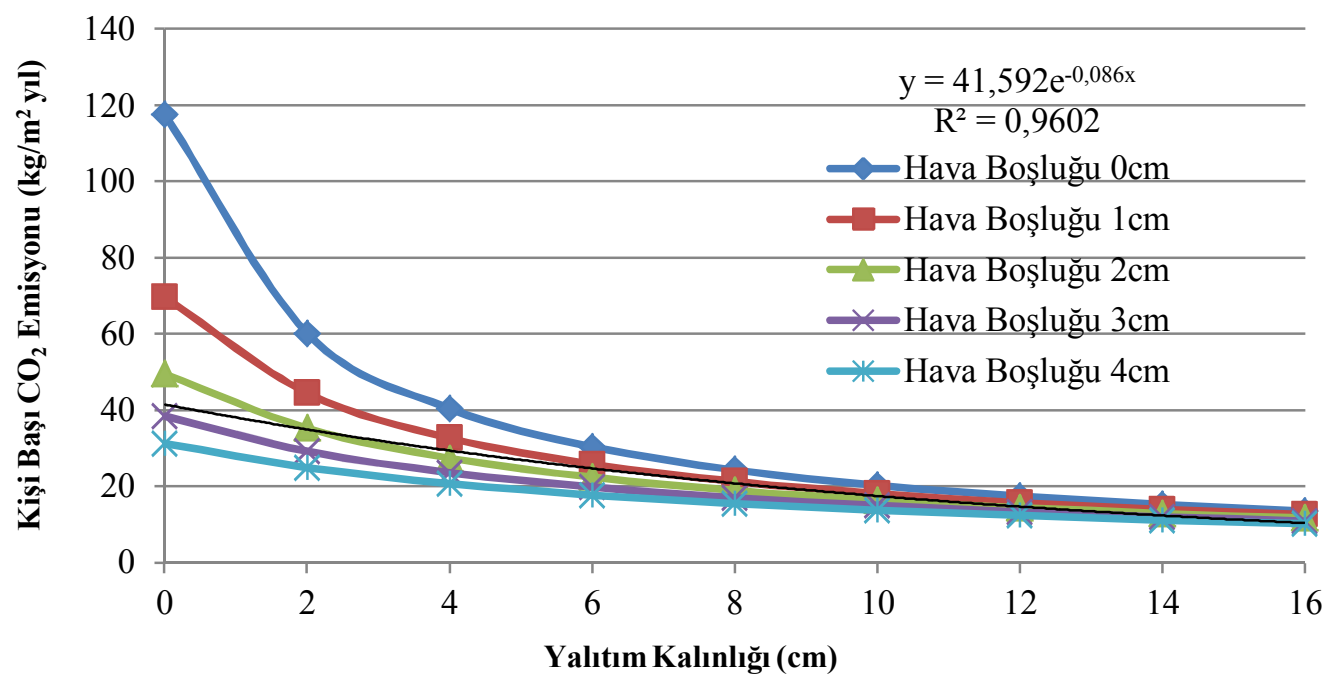

Şekil 4. Doğal gaz için yalıtım malzemesi-hava boşluğu kalınlığına kişi başına düşen yıllık $\mathrm{CO}_{2}$ emisyon miktar1 $\left(\mathrm{kg} / \mathrm{m}^{2} \mathrm{y} 1 \mathrm{l}\right)$ (The amount of $\mathrm{CO}_{2}$ emission $\left(\mathrm{kg} / \mathrm{m}^{2}\right.$ year) according to insulation material and air gap thicknesses for natural gas used as fuel) 
Şekil 3 ve Şekil 4'de her iki yakıt türü ve hava boşluğu kalınlığına göre $\mathrm{CO}_{2}$ salınım ilişkisi görülmektedir. $\mathrm{Bu}$ şekillerde en fazla salınım yalıtımsız yapı bileşenlerinde, daha sonra sırasıyla 12-3 ve $4 \mathrm{~cm}$ yalıtımlı yapı bileşenlerinde olduğu görülmektedir

\subsection{Ankara'daki Konut Sayısı ve Nüfusa Bağlı Baca Gazı Salınımlarının Hesaplanması (The Calculation of Exhaust Emission Dependent on Number of} Building and Population in Ankara )

2014 yılı Ankara ili verilerine göre tüm sektörlerde (mesken, sanayi, ticari, resmi daire ve diğer) elektrik abone sayıs1 2.460.950'dir. Mesken abone sayıs1 ise toplam abone sayısının \%85,3'ü yani 2.099.947 konuttur [30]. Ankara nüfusu 4.956.542 kişidir [28]. Ankara'daki 2.099.947 konutun her birinin $100 \mathrm{~m}^{2}$ olduğu varsayımına göre dış duvar alanı Eşitlik (24)'e göre, yakıt olarak kömür ve doğal gaz kullanıldığı varsayımı ile yakıt tüketimi emisyon miktarı (YTEM) Eşitlik (25)’e göre hesaplanmıştır.

$$
m=n 100 \quad\left[\mathrm{~m}^{2}\right]
$$

$Y T E M=\frac{m \quad e}{P} \quad[\mathrm{~kg} / \mathrm{kişiyıl}]$

Denklemde " $m$ " tüm konutlarım $\mathrm{m}^{2}$ olarak dış duvar alanın1, " $p$ " nüfus sayısın1, " $n$ " konut sayısın1, " $e$ " ise emisyon değerini ifade etmektedir. Ankara'daki konutların tamamında yakıt olarak kömür kullanılması durumunda, farklı yalıtım ve hava boşluğu uygulamalarına göre kişi başı $\mathrm{SO}_{2}$ ve $\mathrm{CO}_{2}$ emisyon miktarı Tablo 8 ve Tablo 9'da görülmektedir. Tablo 8'de binaların tamamı yalıtımsız ve tamamında doğal gaz kullanılması durumunda kişi başı $\mathrm{CO}_{2}$ miktarı $4985,7 \mathrm{~kg}$ olduğu, aynı tabloda yalıtım kalınlığı ve hava boşluğu $4 \mathrm{~cm}$ olması durumunda kişi başına yıllık $\mathrm{CO}_{2}$ salınımı $881,31 \mathrm{~kg}$ olduğu verilmiştir. Burada da yalıtımlı binadaki $\mathrm{CO}_{2}$ salınım miktarı \%82,32 azalmaktadır. Doğal gaz kullanıldığında ise Şekil 5'te yalıtım kalınlığı ve hava boşluğunun artmasıyla $\mathrm{CO}_{2}$ emisyonlarının da azaldığı görülmektedir. Tablo 9'da binaların tamamı yalıtımsız ve kömür kullanılması durumunda kişi başı $\mathrm{SO}_{2}$ miktarı 19,514 kg olduğu, aynı tabloda yalıtım kalınlığı ve hava boşluğu $4 \mathrm{~cm}$ olması durumunda kişi başına yıllık $\mathrm{SO}_{2}$ emisyonunun $3,4487 \mathrm{~kg}$ olduğu görülmektedir. $\mathrm{Bu}$ sonuçlara göre yalıtımlı binada $\mathrm{SO}_{2}$ salınım miktarı \%82,32 azalmaktadır. Tablo 10 'de binaların tamamı yalıtımsız ve kömür kullanılması durumunda kişi başı $\mathrm{SO}_{2}$ miktarı 19,514 $\mathrm{kg}$ olduğu, aynı tabloda yalıtım kalınlığı ve hava boşluğu $4 \mathrm{~cm}$ olması durumunda kişi başına yıllık $\mathrm{SO}_{2}$ emisyonunun $3,4487 \mathrm{~kg}$ olduğu görülmektedir. $\mathrm{Bu}$ sonuçlara göre yalıtımlı binada $\mathrm{SO}_{2}$ salınım miktarı \%82,32 azalmaktadır.

Tablo 10'da binaların tamamı yalıtımsız ve kömür kullanılması durumunda kişi başı $\mathrm{CO}_{2}$ miktarı 9482,95 $\mathrm{kg}$ olduğu, yalıtım kalınlığı ve hava boşluğu $4 \mathrm{~cm}$ olması durumunda kişi başına yıllık $\mathrm{CO}_{2}$ salınımın $1675,87 \mathrm{~kg}$ olduğu görülmektedir. $\mathrm{Bu}$ sonuçlara göre yalıtımlı binadaki $\mathrm{CO}_{2}$ salınım miktarı \%82,32 azalmaktadır. Tablo 9 ve 10 'da $\mathrm{SO}_{2}$ ve $\mathrm{CO}_{2}$ emisyon miktarları farklı olmasına rağmen yalıtım kalınlığına bağlı emisyon değerlerinde ki azalmanın oransal olarak aynı olduğu görülmektedir. $\mathrm{Bu}$ yaklaşımla Şekil 6 ve 7'de $\mathrm{SO}_{2}$ ve $\mathrm{CO}_{2}$ salınım eğimlerinin birbirine yaklaşık olduğu görülmektedir.

Tablo 8. Doğal gaz için kişi başı $\mathrm{CO}_{2}$ emisyon miktarı (kg/kişi yıl) (The amount of $\mathrm{CO}_{2}$ emission (kg / person year) in case of using natural gas as fuel)

\begin{tabular}{|c|cccccccccc|}
\hline \multirow{2}{*}{$\begin{array}{c}\text { Hava } \\
\text { Boşluğu } \\
(\mathbf{c m})\end{array}$} & \multicolumn{7}{|c|}{ CO $_{\mathbf{c}}$ Emisyon Miktarı ( kg/kişi yıl) } \\
\cline { 2 - 10 } & 0 & 2 & 4 & 6 & 8 & 10 & 12 & 14 & 16 \\
\hline 0 & $\mathbf{4 9 8 5 , 7}$ & 2551,11 & 1714,09 & 1290,63 & 1034,95 & 863,829 & 741,262 & 649,155 & 577,409 \\
1 & 2955,16 & 1887,49 & 1386,54 & 1095,73 & 905,763 & 771,930 & 672,555 & 595,848 & 534,847 \\
2 & 2099,92 & 1497,85 & 1164,1 & 951,977 & 805,245 & 697,704 & 615,504 & 550,631 & 498,129 \\
3 & 1628,6 & 1241,562 & 1003,16 & 841,5648 & 724,8082 & 636,5016 & 567,3757 & 511,7934 & 466,1296 \\
4 & 1330,06 & 1060,16 & $\mathbf{8 8 1 , 3 1}$ & 754,102 & 658,981 & 585,17 & 526,227 & 478,073 & 437,992 \\
\hline
\end{tabular}

Tablo 9. Kömür için kişi başı $\mathrm{SO}_{2}$ emisyonmiktarı (kg/kişi yıl).(The amount of $\mathrm{SO}_{2}$ emission (kg / person.year) for coal used as fuel)

\begin{tabular}{|c|ccccccccc|}
\hline \multirow{2}{*}{$\begin{array}{c}\text { Hava Boşluğu } \\
(\mathbf{c m})\end{array}$} & \multicolumn{8}{|c|}{ SO $_{2}$ Emisyon Miktarı ( kg/kişi yıl) } \\
\cline { 2 - 10 } & 0 & 2 & 4 & 6 & 8 & 10 & 12 & 14 & 16 \\
\hline 0 & 19,514 & 9,9842 & 6,7081 & 5,0508 & 4,0501 & 3,3804 & 2,9007 & 2,5403 & 2,2595 \\
1 & 11,564 & 7,3861 & 5,4258 & 4,2878 & 3,5444 & 3,0207 & 2,6318 & 2,3316 & 2,0929 \\
2 & 8,2173 & 5,8613 & 4,5553 & 3,7252 & 3,1510 & 2,7302 & 2,4085 & 2,1547 & 1,9492 \\
3 & 6,3730 & 4,8584 & 3,9255 & 3,2931 & 2,8363 & 2,4907 & 2,2202 & 2,0027 & 1,8240 \\
4 & 5,2047 & 4,1485 & 3,4487 & 2,9509 & 2,5787 & 2,2898 & 2,0592 & 1,8707 & 1,7139 \\
\hline
\end{tabular}




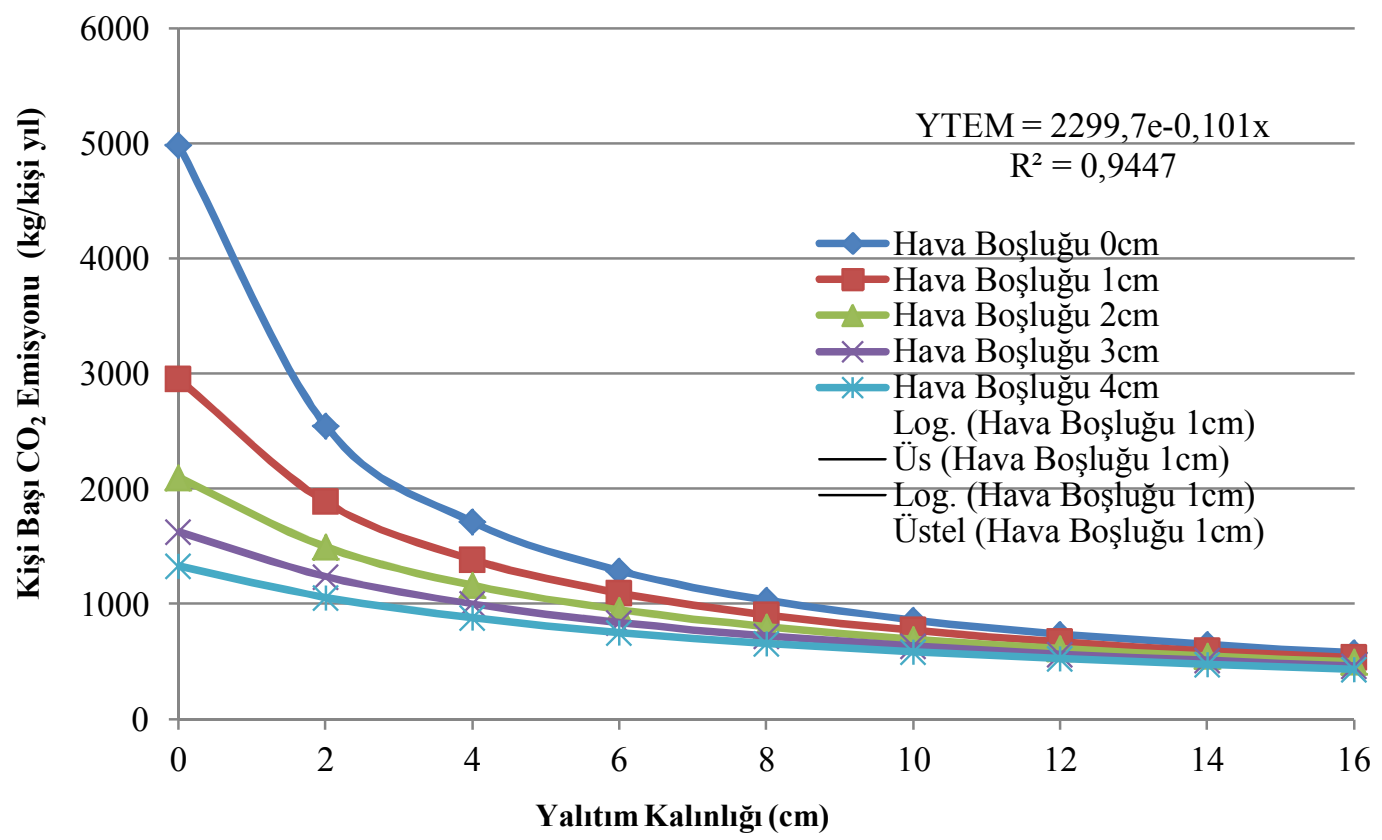

Şekil 5. Doğal gaz için yalıtım malzemesi ve hava boşluğu kalınlığına göre kişi başı $\mathrm{CO}_{2}$ emisyon dağılımı $\left(\mathrm{kg} / \mathrm{m}^{2} \mathrm{yll}\right)$ (The distribution of $\mathrm{CO}_{2}$ emission per person according to insulation material and air gap for natural gas used as fuel)

Tablo 10. Kömür için kişi başı $\mathrm{CO}_{2}$ emisyonmiktarı (kg/ kişiyıl) (The amount of $\mathrm{CO}_{2}$ emission (kg / person.year) for coal used as fuel)

\begin{tabular}{|c|ccccccccc|}
\hline \multirow{2}{*}{ Hava Boșluğu (cm) } & \multicolumn{7}{|c|}{ CO $_{\mathbf{2}}$ Emisyon Miktarı ( kg/kişi yıl) } \\
\cline { 2 - 10 } & \multicolumn{7}{|c|}{ Yalıtım Kalınlığı (cm) } \\
\cline { 2 - 10 } & 0 & 2 & 4 & 6 & 8 & 10 & 12 & 14 \\
\hline 0 & $\mathbf{9 4 8 2 , 9 5}$ & 4851,70 & 3259,72 & 2454,38 & 1968,13 & 1642,69 & 1409,60 & 1234,44 & 1098,00 \\
1 & 5619,43 & 3589,18 & 2636,60 & 2083,60 & 1722,36 & 1467,87 & 1278,90 & 1133,04 & 1017,04 \\
2 & 3993,13 & 2848,26 & 2213,60 & 1810,24 & 1531,22 & 1326,72 & 1170,41 & 1047,05 & 947,223 \\
3 & 3096,88 & 2360,90 & 1907,57 & 1600,28 & 1378,26 & 1210,34 & 1078,89 & 973,206 & 886,373 \\
4 & 2529,20 & 2015,95 & $\mathbf{1 6 7 5 , 8 7}$ & 1433,97 & 1253,09 & 1112,73 & 1000,65 & 909,084 & 832,869 \\
\hline
\end{tabular}

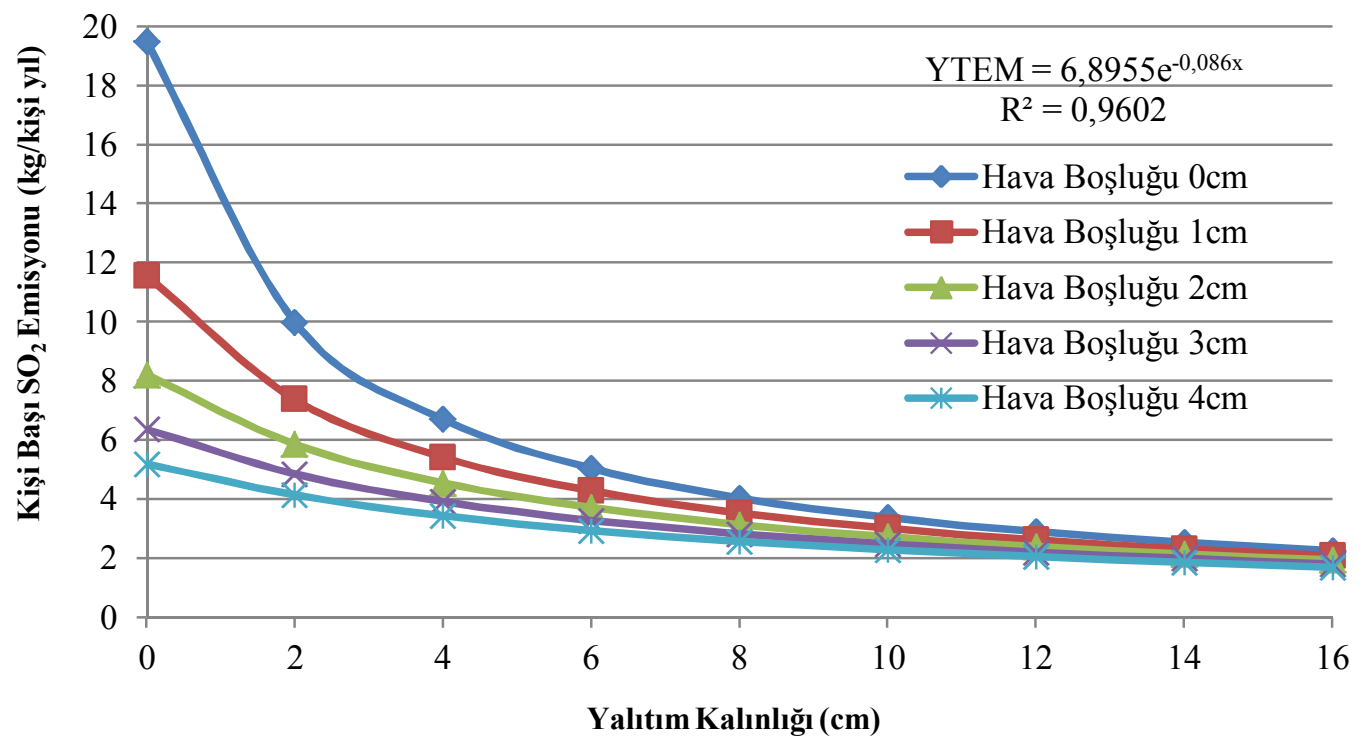

Şekil 6. Kömür için yalıtım malzemesi ve hava boşluğu kalınlığına göre kişi başı $\mathrm{SO}_{2}$ emisyon dağılımı (kg/ kişi yıl) (The distribution of $\mathrm{SO}_{2}$ emission per person according to insulation material and air gap for coal used as fuel (kg/ person.year) 


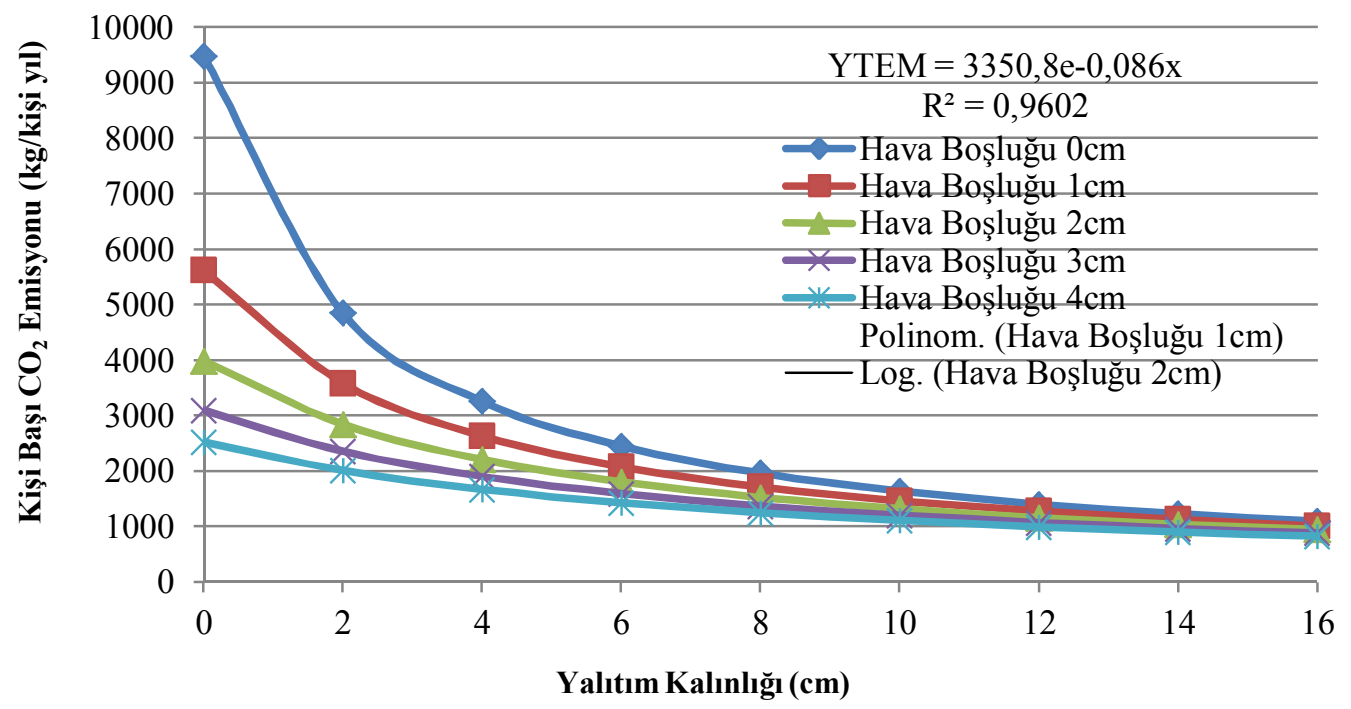

Şekil 7. Kömür için yalıtım malzemesi ve hava boşluğu kalınlığına göre kişi başı $\mathrm{CO}_{2}$ emisyon dağılımı ( $\mathrm{kg} / \mathrm{kişi} \mathrm{y1l)} \mathrm{(The} \mathrm{distribution} \mathrm{of} \mathrm{CO}_{2}$ emission per person according to insulation material and air gap for coal used as fuel (kg / person year)

\section{SONUÇLAR (CONCLUSIONS)}

Bu çalışmada yakıt olarak doğal gaz kullanıldığında, yalıtım malzemesi XPS ile birlikte duvar bileşenine 4 $\mathrm{cm}$ hava boşluğu ilave edildiğinde XPS kalınlığını \% 63 oranında, GÖS'ni 2.268 ay, toplam maliyeti de $\% 28$ oranında azaltmaktadır. Yıllık kazanç ise \%96 arttığı tespit edilmiştir Yakıt olarak kömür kullanıldığın da XPS kalınlığı \%54, GÖS'ni 1.608 ay, toplam maliyette \% 24 azalmaktadır. Yıllık kazancın ise $\mathrm{m}^{2}$ başına \%94 arttığı hesaplanmıştır. Ankara'daki binaların tamamı yalıtımsız ve kömür kullanılması durumunda kişi başı $\mathrm{SO}_{2}$ miktarıyla, yalıtım kalınlığı $4 \mathrm{~cm}$ ve hava boşluğunun da $4 \mathrm{~cm}$ olması durumunda kişi başına yıllık $\mathrm{SO}_{2}$ ve $\mathrm{CO}_{2}$ salınımı \%82,32 azalmaktadır. Dört $\mathrm{cm}$ yalıtım kalınlığı, $4 \mathrm{~cm}$ hava boşluğu ve yakıt olarak doğal gaz kullanılması durumunda, $\mathrm{CO}_{2}$ emisyonu $881,31 \mathrm{~kg} /$ kişi yıl, kömür kullanılması durumunda $\mathrm{CO}_{2}$ emisyonu 1675,87 $\mathrm{kg} /$ kişi yıldır. Ankara ili 2014'deki nüfus, meskene ait elektrik abone sayıları temel alınarak yapılan hesaplamalara göre Ankara toplam dıș duvar alanı 209.994.700 $\mathrm{m}^{2}$ olarak belirlenmiştir. Bu dış duvar alanına göre yakıt olarak doğalgaz kullanılması durumunda yalitımsız binada 24.711 .831 ton/yll $\mathrm{CO}_{2}$ salınmaktadır. Yalıtım kalınlığ $4 \mathrm{~cm}$ ve $4 \mathrm{~cm}$ hava boşluğu uygulamasıyla 4.368 .250 ton/yil $\mathrm{CO}_{2}$ salınacağı hesaplanmıştır. $\mathrm{Bu}$ durumda $\mathrm{CO}_{2}$ salınımının \%83 azalacağı hesaplanmıştır. Kömür kullanılması durumunda yalıtım yapılmadan yılda 96.721 .961 ton/y1l $\mathrm{SO}_{2}, 47.002 .640$ ton/y1l $\mathrm{CO}_{2}$ salınmaktadır. Yalıtım kalınlığ $4 \mathrm{~cm}$ ve4 $\mathrm{cm}$ hava boşluğu uygulamasıyla 17.094 ton/yll $\quad \mathrm{SO}_{2}$ ve 83.065.220 ton/yıl $\mathrm{CO}_{2}$ salınacağı hesaplanmıştır. $\mathrm{Bu}$ durumda $\mathrm{CO}_{2}$ oranının $\% 83$ azaltılabileceği görülmüştür. 209.994.700 m² dış duvar alanına göre; yakıt olarak doğal gaz, yalıtım malzemesi olarak
$3.4 \mathrm{~cm}$ XPS, $4 \mathrm{~cm}$ hava boşluğuna göre yıllık kazanç 317.091.997 TL'den 8.651.361.651 TL'ye yükselmiştir. Yakıt olarak kömür, yalıtım malzemesi olarak $5 \mathrm{~cm}$ XPS, $4 \mathrm{~cm}$ hava boşluğuna göre ylllık kazanç 299.242.448 TL'den 5.157.679.827 TL'ye yükselmiştir. Dolayısıyla OYK'nın doğru tespit edilmesi çevresel ve ekonomik açıdan çok önem arz etmektedir. Bu nedenle yalıtımsız binalar için yalıtımı özendirmek adına kısmen hibe ve uzun vadeli faizsiz kredilerle devlet teşvikine ihtiyaç vardır.

\section{SEMBOLLER VE KISALTMALAR (SYMBOLS AND ABBREVIATIONS)}

$C_{y} \quad$ Yalitım maliyet [TL/m3]

$C_{f} \quad$ Yakıt maliyet $[\mathrm{TL} / \mathrm{kg}, \mathrm{TL} / \mathrm{m} 3, \mathrm{TL} / \mathrm{kWh}]$

EA Isıtma için gerekli yıllık enerji miktarı [J/m2y1l

$g \quad$ Enflasyon oranı [\%]

GÖS Geri ödeme süresi [Yıll]

IDS Isitma derece Saat $\left[{ }^{\circ} \mathrm{C}\right.$-saat $]$

$i \quad$ Faiz oran1 [\%]

$k \quad$ Yalıtım malzemesinin 1 sil iletim katsayısı $[\mathrm{W} / \mathrm{mK}]$

LCCA Ömür maliyet analizi

LHV Yakıtın alt isıl değeri $[\mathrm{J} / \mathrm{kg}, \mathrm{J} / \mathrm{m} 3, \mathrm{~J} / \mathrm{kWh}]$

$m_{f} \quad$ Y1llık yakıt tüketimi $[\mathrm{kg} / \mathrm{m} 2 \mathrm{y} 11, \mathrm{~m} 3 / \mathrm{m} 2 \mathrm{y} 1 \mathrm{l}$, $\mathrm{kWh} / \mathrm{m} 2 \mathrm{yll}]$

$P P \quad$ Geri ödeme süresi [yıl]

$P_{1} \quad$ Şimdiki değer faktörü

$q \quad$ Y1llı 1 si kaybi [MJ/m2yıl]

$r \quad$ Gerçek faiz oranı

$R \quad$ Isıl direnç $[\mathrm{m} 2 \mathrm{~K} / \mathrm{W}]$

$T_{b} \quad$ Mahal sicakl $\lg 1\left[{ }^{\circ} \mathrm{C}\right]$

$T_{0} \quad$ Ortalama dış sıcaklık $\left[{ }^{\circ} \mathrm{C}\right]$

$U$ Toplam isı geçiş katsayısı [W/mK]

$\eta \quad$ Yakma sisteminin verimi

$x \quad$ Yalıtım Kalınlığı $[\mathrm{m}]$ 


\section{KAYNAKLAR (REFERENCES)}

1. Al-Homoud, M. S., "Performance characteristics and practical applications of common building thermal insulation materials", Building and Environment, Cilt 40, 353-366, 2005.

2. Bolattürk, A., "Determination of optimum insulation thickness forbuilding walls with respect to various fuels and climate zones in Turkey", Applied Thermal Engineering, Cilt 26 No 11-12, 1301-1309, 2006.

3. Keçebas, A. ve Kayfeci, M., "Effect on optimum insulation thickness, cost and saving of storage desing temperature in cold storage in Turkey", Energy Education Science and Technology, Cilt 25, No 2, 117-127, 2010.

4. Gölcü, M., Dombaycı, A. ve Abalı, S., "Denizli için optimum yalıtım kalınlığının enerji tasarrufuna etkisi ve sonuçları", Journal of the Faculty of Engineering and Architecture of Gazi University, Cilt 21, No 4, 639-644, 2006.

5. Öztuna, S. ve Dereli E., "Edirne ilinde optimum duvar yalıtım kalınlığının enerji tasarrufuna etkisi", Trakya Univ J. Sci, Cilt 10, No 2, 139147, 2009.

6. Deniz, E., Gürel, A. E., Daşdemir, A. ve Çamur, D., "Fuel consumption and influences of external wall optimum insulation thickness to owning cost of energy", Karabuk Unv, Technology, Cilt 12, No 4, 283-290, 2009.

7. Yildiz, A., Gürlek, G., Erkek, M. ve Özbalta, N., "Economical and environmental analyses of thermal insulation thickness in buildings", Isı Bilimi ve Tekniği Dergisi, Cilt 28, No 2, 25-34, 2008.

8. Yu, J., Yang, C., Tian, L., ve Liao, D., "A study on optimum insulation thickness of external walls in hot summer and cold winter zone of China", Applied Energy, Cilt 86,No 4, 2520-2529, 2009.

9. Daouas, N., Hassen, H. ve A1ssia, H., "Analytical periodic solution for the study of thermal performance and optimum insulation thickness of building walls in Tunisia", Applied Thermal Engineering, Cilt 30, No 4, 319-326, 2010.

10. Al-Khawaja, M. J., "Determination and selecting the optimum thickness of insulation for buildings in hot countries by accounting for solar radiation", Applied Thermal Engineering, Cilt 24, No 17-18, 2601-2610, 2004.

11. Çay, Y., "The impact of determination of oprimum insulation thickness on energy saving for different climatic regions of Turkey", Energy Education Science and Technology, Cilt 28, No 10, 83-94, 2011.

12. Balo, F. ve Uçar, A., "Yapıların dış duvarlarında optimum yalıtım kalınlığının üç farklı metotla tespiti”, 10. Ulusal Tesisat Mühendisliği Kongresi, İzmir, 1: 271-285 2011.
13. Aytaç A. ve Aksoy U. T., "Enerji tasarrufu için dış duvarlarda optimum yalıtım kalınlığg ve 1sıtma maliyeti ilişkisi", Journal of the Faculty of Engineering and Architecture of Gazi University, Cilt 21, No 4, 753-758, 2006.

14. Mahlia, T. M. I. ve Iqbal, A., "Cost benefits analysis and emission reductions of optimum thickness and air gaps fors elected insulation materials for building walls in Maldives", Energy, Cilt 35, No 5, 2242-2250, 2010.

15. Gürel, A. E. ve Daşdemir A., "Economical and Enviromental Effects of Thermal Insulation Thicness in Four Different Climatic Regions of Turkey”, IJRER, Cilt 1, 1-10, 2011.

16. Kurt, H., "The usage of airgap in the composite wall for energy saving and air pollution", Environmental Progress \& Sustainable Energy, Cilt 30, 450-458, 2011.

17. Mihlayanlar, E., Umaroğulları, F. ve Kartal, S., "Binalarda enerji verimliliği açısından 1sı yalıtımının hava kirliliğine etkisi - Edirne örneği" 10. Ulusal Tesisat Mühendisliği Kongresi, İzmir, 2111-2119, 2011.

18. Mahlia, T. M. I. ve Iqbal, A., "Cost benefits analysis and emission reductions of optimum thickness and air gaps for selected insulation materials for building walls in Maldives", Energy, Cilt 35, 2242-2250, 2010.

19. Deniz, E.,Gürel, A. E., Daşdemir, A. ve Çamur, D., "Fuel consumption and influences of external wall optimum insulation thickness to owning cost of energy", Karabuk University, Technology, Cilt 12, No 4, 283-290, 2009.

20. TS 500 "Betonarme Yapıların Tasarımı ve Yapım Kuralları" TSE, 4 Haziran 2004.

21. Özel M., "Dört Farklı İl İçin Optimum Yalıtım Kalınlıklarının Belirlenmesi ve ÇevreselAnaliz", Makine Teknolojileri Elektronik Dergisi, Cilt 10, 1-17, 2013.

22. Hasan A., "Optimizing Insulation Thickness for Buildings Using Life Cycle Cost" Applied Energy, Cilt 63, 115-124, 1999.

23. Ozkahraman, H. T., Bolatturk, A., "The Use of Tuff Stone Cladding in Buildings for Energy Conservation", Construction and Building Materials, Cilt 20, 435-440, 2005.

24. Yıldız, A., Gürlek, G., Erkek, M. ve Özbalta, N. "Economical and environmental Analyses of thermal insulation thickness in buildings", Isı Bilimi ve Tekniği Dergisi, Cilt 28, 25-34, 2008.

25. Al-Sanea S. A., Zedan M. F., Al-Ajlan S. A. ve Abdul Hadi A. S., Heat transfer characteristics and optimum insulation thickness for cavity walls, J. Thermal Envelope and Building Science, Cilt 26, No 3, 285-307, 2003.

26. Hasan A., Optimizing insulation thickness for buildings using life cycle cost, Applied Energy, Cilt 63, 115- 124, 1999. 
27. İnternet: Türkiye Cumhuriyeti Merkez Bankası, http://www.tcmb.gov.tr/wps/wcm/connect/tcmb+t $\mathrm{r} / \mathrm{tcmb}+\mathrm{tr} / \mathrm{main}+\mathrm{menu} /$ para+politikasi/merkez $+\mathrm{ba}$ nkasi+faiz+oranlari, 2014

28. İnternet: Türkiye İstatistik Kurumu, https://biruni.tuik.gov.tr/medas $/ \mathrm{kn}=95 \&$ locale $=\operatorname{tr}$, 2014.
29. Kadıoğlu, S. ,Tellioğlu Z., "Enerji kaynaklarının kullanımı ve çevreye etkileri", TMМOB Türkiye 1. Enerji Sempozyumu, Ankara, 55-67, 12-14 Kasim 1996.

30. Internet: Türkiye Elektrik Dağıtım Anonim Şirketi,http://www.tedas.gov.tr/sx.web.docs/tedas /docs/faaliyetrapor/2014 yili faaliyet raporu.pdf 